\title{
Concurrent eosinophilia and IgG4-related disease in a child: A case report and review of the literature
}

\author{
CAN CHEN, KUANG CHEN, XILIAN HUANG, KAILE WANG and SHENXIAN QIAN \\ Department of Hematology, Hangzhou First People's Hospital, Hangzhou, Zhejiang 310006, P.R. China
}

Received September 27, 2016; Accepted November 16, 2017

DOI: $10.3892 /$ etm.2018.5743

\begin{abstract}
The current study presents the case of a 9-year-old Chinese boy who presented with eosinophilia and elevated serum levels of immunoglobulin G4 (IgG4). A bone marrow puncture identified an elevated eosinophil rate of $23 \%$ (normal range, $<5 \%$ ), which indicated eosinophilia. However, gene analysis, fluorescent in situ hybridization and other examinations, including bone marrow aspiration, blood routine, auto-antibody tests and parasitic and allergens screening, contradicted a diagnosis of secondary or clonal eosinophilia. Furthermore, the patient exhibited multiple lymph node swelling and a lymph biopsy strongly indicted a pathological diagnosis of IgG4-related disease (IgG4-RD). His peripheral blood flow cytometry confirmed an elevated count of plasmablasts, which is specific to IgG4-RD. The patient responded well to therapy with prednisone and remained healthy in all follow-ups. By taking all these factors into consideration, the boy was diagnosed with IgG4-RD. It is difficult to distinguish IgG4-RD from hypereosinophilic syndrome and the potential association between the two remains unclear. However, the present case study serves as a reminder that IgG4-RD may occur in children and medical professionals should not neglect this possibility.
\end{abstract}

\section{Introduction}

Hypereosinophilic syndrome (HES) is defined as the presence of a peripheral blood eosinophil (PBE) count of $\geq 1.5 \times 10^{9} / 1$ for at

Correspondence to: Professor Shenxian Qian, Department of Hematology, Hangzhou First People's Hospital, 216 Huansha Road, Hangzhou, Zhejiang 310006, P.R. China

E-mail: sysxqian@163.com

Abbreviations: IgG4, immunoglobulin G4; IgG4-RD, immunoglobulin G4-related disease; HES, hypereosinophilic syndrome; IHES, idiopathic hypereosinophilic syndrome; EOS, eosinophils; IL, interleukin; TNF, tumor necrosis factor; CRP, C-reactive protein; FISH, fluorescent in situ hybridization; CT, computed tomography; MRI, magnetic resonance imaging; AIP, autoimmune pancreatitis; MCD, multiple Castleman's disease

Key words: child, hypereosinophilic syndrome, IgG4-related disease, multiple Castleman's disease least 6 months [a shorter duration is acceptable in the presence of symptoms that require eosinophil (EOS)-lowering therapy] with clinical end-organ damage (1). The age-adjusted incidence rate of HES was $\sim 0.36$ per 1,000,000 people between 2001 and 2005, according to the Surveillance, Epidemiology and End Results database (2). HES may be divided into three subtypes, namely primary (clonal), secondary (reactive) and idiopathic eosinophilia (IHES), according to its pathogenesis (1). Numerous diseases may cause secondary eosinophilia, including infection (particularly by tissue-invasive parasites), allergy/atopy, hypersensitivity, drug reactions and collagen-vascular disease $(3,4)$. Control of the primary disease is therefore essential for the treatment of secondary eosinophilia. Furthermore, the evaluation of a primary bone marrow disorder should be conducted if secondary causes of eosinophilia are excluded (5). Screening for factor interacting with PAPOLA and CPSF1 (FIP1L1)-platelet-derived growth factor receptor (PDGFR) A using fluorescent in situ hybridization (FISH) or polymerase chain reaction (PCR) and cytogenetic analysis for reciprocal translocations involving 4q12 (PDGFRA), 5q31-33 (PDGFRB), 8p11-12 (fibroblast growth factor receptor 1; FGFR1) or 9p24 (janus kinase 2; JAK2) are necessary for the diagnosis of primary eosinophilia (5). However, IHES is a diagnosis made when the possibility of secondary and primary eosinophilia are excluded (5). Lymphocyte-variant HSE is a subtype of primary eosinophilia characterized by an abnormal T-cell population (6). Imatinib is a recommended treatment for patients exhibiting rearrangements of PDGFRA or PDGFRB $(7,8)$ and corticosteroids are the first-line therapy for patients with lymphocyte-variant hypereosinophilia and IHES $(5,9)$. Interferon- $\alpha$ targeted antibodies and hydroxyurea, as well as other chemotherapies, may clinically benefit patients with primary eosinophilia that have variable response durability (10-12).

Immunoglobulin G4 (IgG4)-related disease (IgG4-RD) is a recently defined clinical illness that is characterized by tissue infiltration by IgG4-positive plasma cells and/or elevated serum IgG4 concentration alongside chronic inflammation and primarily affects middle aged or elderly men (13). Additionally, IgG4-RD encompasses a variety of conditions, including Mikulicz's syndrome, chronic sclerosing sialadenitis, hypophysitis, Riedel thyroiditis, inflammatory artificial tumors, chronic interstitial pneumonitis, interstitial nephritis, autoimmune pancreatitis, retroperitoneal fibrosis, sclerosing cholangitis, sclerosing cholecystitis, prostatitis and lymphadenopathy (13). 
However, the pathogenesis, diagnostic criteria and role of increased serum IgG4 remain controversial (14).

The present study reported the case of a 9 year-old Chinese boy who presented with eosinophilia and elevated serum levels of IgG4. Following systematic evaluation, he was diagnosed with HES and IgG4-associated disease. Corticosteroids were administered for treatment and were proven to be effective and the patient remains asymptomatic.

\section{Case report}

A 9-year-old Chinese boy was admitted to the Hangzhou First People's Hospital (Hangzhou, China) due to suspected leukocytosis and eosinophilia for $\sim 1$ week on July 17, 2015. The appropriate examinations were performed in the hospital and written informed consent was obtained from the patient's family. The results of a routine blood test identified an abnormal EOS count of $7.01 \times 10^{9} / 1$ (normal range, 0.02-0.52 $\times 10^{9} / 1$ ). A high erythrocyte sedimentation rate $(64 \mathrm{~mm} / \mathrm{h}$; normal range, 0-15 mm/h), high IgG (41.8 g/l; normal range, 6.09-12.85 g/l) and high $\operatorname{IgE}(1,755.5 \mathrm{kU} / \mathrm{l}$; normal range, $<87 \mathrm{kU} / \mathrm{l})$ counts were also observed. However, the $\operatorname{IgA}(1.84 \mathrm{~g} / \mathrm{l}$; normal range, $0.52-2.16 \mathrm{~g} / \mathrm{l})$ and $\operatorname{IgM}(2.33 \mathrm{~g} / \mathrm{l}$; normal range, 0.67-2.48 g/l) counts were within the normal ranges. An upper abdominal $\mathrm{B}$ ultrasonography identified multiple peripancreatic hypoechoic nodules. Furthermore, an ultrasound of the mesenteric lymph nodes revealed multiple mesenteric lymph nodes, some of which were enlarged. However, the echocardiography was normal. A bone marrow puncture identified an elevated EOS rate of $23 \%$ (normal range, $<5 \%$ ), which indicated eosinophilia. The boy was permitted to leave the hospital when the EOS count was reduced to $2.94 \times 10^{9} / 1$ following therapy with anti-allergic drugs administered orally ( $4 \mathrm{mg}$ chlorphenamine maleate three times a day for 1 week and $4 \mathrm{mg}$ singulair per day for 1 month) and oral antiparasitic drugs (zentel, $200 \mathrm{mg}$ per day for 3 days). The boy had no history of allergies, contact with pets or stay in an epidemic area and he did not have a fever, cough, expectoration, abdominal pain or diarrhea.

On March 31, 2016, the patient was admitted to the hospital again due to long-term eosinophilia and right posterior auricular lymph node swelling. A physical examination identified enlargement of several peanut-sized lymph nodes in the retroauricular region and on both sides of the neck. The nodes were homogeneous, smooth-surfaced, mobile and not tender. A routine blood examination indicated an increased EOS count of $12.6 \times 10^{9} / 1$ compared with that detected previously and high $\operatorname{IgE}(875.3 \mathrm{kU} / \mathrm{l}), \mathrm{IgG}(43.9 \mathrm{~g} / \mathrm{l})$ and $\operatorname{IgG} 4$ (14.2 g/l; normal range, 0.03-2.01 g/l) counts. Allergic source tests identified an allergy to house dust mites due to elevated $\operatorname{IgE}(\mathrm{IgE} ; 16.26 \mathrm{kU} / \mathrm{l}$; normal range, $<0.35 \mathrm{kU} / \mathrm{l})$. A T-SPOT test for tuberculosis and the results of autoantibody tests [including anti-laminoid antibody, anti-nucleosome antibody, anti-Ro52 antibody, anti-PM-Scl antibody, anti-Scl-70 antibody, antinuclear antibody, anti-Sm antibody, anti-SSB antibody, anticardiolipin antibody (IgA, IgG and IgM), anti-actin antibody, anti-PCNA antibody, anti-centromere antibody, anti-ribosomal $\mathrm{P}$ protein antibody, anti-mitochondrial (M2) antibody, anti-Jo1 antibody, anti-U1-nRNP antibody, anti-SSA antibody, anti-histone antibody and anti-double stranded DNA antibody tests] were all negative. Superficial lymphadenopathy B ultrasonography identified several smooth-surfaced hypoechoic nodules with irregular shapes in the bilateral neck (the largest one being $3.2 \times 1.2 \mathrm{~cm}$ ). A magnetic resonance imaging examination of the head displayed abnormal signals in the right thalamus, possibly indicating an eosinophilic granuloma. A lung computed tomography (CT) scan identified several small nodules in the right lung and an upper abdominal CT scan detected abnormal lesions in the left liver and spleen.

The patient subsequently underwent a cervical lymph node biopsy. All specimens were fixed in $4 \%$ buffered formalin at room temperature $\left(37^{\circ} \mathrm{C}\right)$ for $24 \mathrm{~h}$ and added to paraffin-embedded blocks. Sections were cut to a thickness of $4 \mu \mathrm{m}$ and stained using hematoxylin and eosin (H\&E). Following washing, sections were soaked in hematoxylin for $5 \mathrm{~min}$ at $37^{\circ} \mathrm{C}$, washed with water, then subsequently washed with hydrochloric acid alcohol for $30 \mathrm{sec}$ and then with water for $5 \mathrm{~min}$ at $50^{\circ} \mathrm{C}$. Finally, sections were stained with eosin for $2 \mathrm{~min}$ at $37^{\circ} \mathrm{C}$. EOS, plasma cells and macrophages were counted in 10 random high power fields of view using a light microscope at a magnification of $\mathrm{x} 400$ ). The EOS was identified following $H \& E$ staining. Plasma cells and macrophages were identified by H\&E staining combined with staining for cluster of differentiation (CD)138 (cat. no. EP201; 1:300) and CD68 (cat. no. KP1; 1:100), respectively. The number of $\mathrm{IgG}+$ and IgG4+ cells were counted from 10 different high-power fields of view (magnification, $x 400$ ). The quantification of cells was conducted manually using 10 high power fields, and 100 cells were counted for every HPF. The percentage of cells was then calculated. Histomorphological results were replicated three experienced pathologists. The pathological results identified high EOS infiltration (>80\% infiltrating cells) in the lymph nodes (Fig. 1A). The infiltrate also contained CD138+ plasma cells ( $<20 \%$ infiltrating cells; Fig. 1B) and a small number of multinucleate giant cells ( $<2 \%$ infiltrating cells). However, no clear lymph node fibrosis as detected using H\&E, was observed.

Immunohistochemical analysis of the patient's cervical lymph node was then conducted. Samples were fixed in $4 \%$ paraformaldehyde- $0.1 \mathrm{mmol} / 1$ phosphate buffer at $4^{\circ} \mathrm{C}$ for $24 \mathrm{~h}$ and then underwent paraffin blocking and were cut to a thickness of $3 \mu \mathrm{m}$. Sections were then place in water at $40^{\circ} \mathrm{C}$, picked up using glass slides and dried using an incubator at $37^{\circ} \mathrm{C}$ for $8 \mathrm{~h}$ ). Glass slides were then washed with $100 \%$ xylene and rehydrated in descending alcohol series (100, 95, 90, 80 and 70\%) for $10 \mathrm{~min}$ each. Samples were washed using water and $3 \% \mathrm{H}_{2} \mathrm{O}_{2}$ for $10 \mathrm{~min}$. Following this, citrate buffer was added, heated for 3 min until boiled and cooled to room temperature. This temperature protocol was then repeated. The citrate buffer was removed and the samples were washed with water twice and subsequently washed with PBS for $5 \mathrm{~min}$. Samples were then added to $10 \%$ goat serum (cat. no. C-0005; Jiangxi Haoran Bio-Pharma Co., Ltd., Jiangxi, China; dilution by PBS) for $10 \mathrm{~min}$ at $37^{\circ} \mathrm{C}$. Primary antibodies were subsequently added and incubated for $1 \mathrm{~h}$ at $37^{\circ} \mathrm{C}$. Samples were then washed three times with PBS for 5 min. Horseradish peroxidase conjugated secondary antibodies were added (1\% BSA-PBS dilution) and incubated for $30 \mathrm{~min}$ at $37^{\circ} \mathrm{C}$. Samples were then washed three times with PBS for 5 min. DAB was then applied for 1 min and observed using a light microscope (magnification, $\mathrm{x} 400$ ). Immunohistochemical analysis was performed using an automated Benchmark XT slide stainer (Ventana Medical 

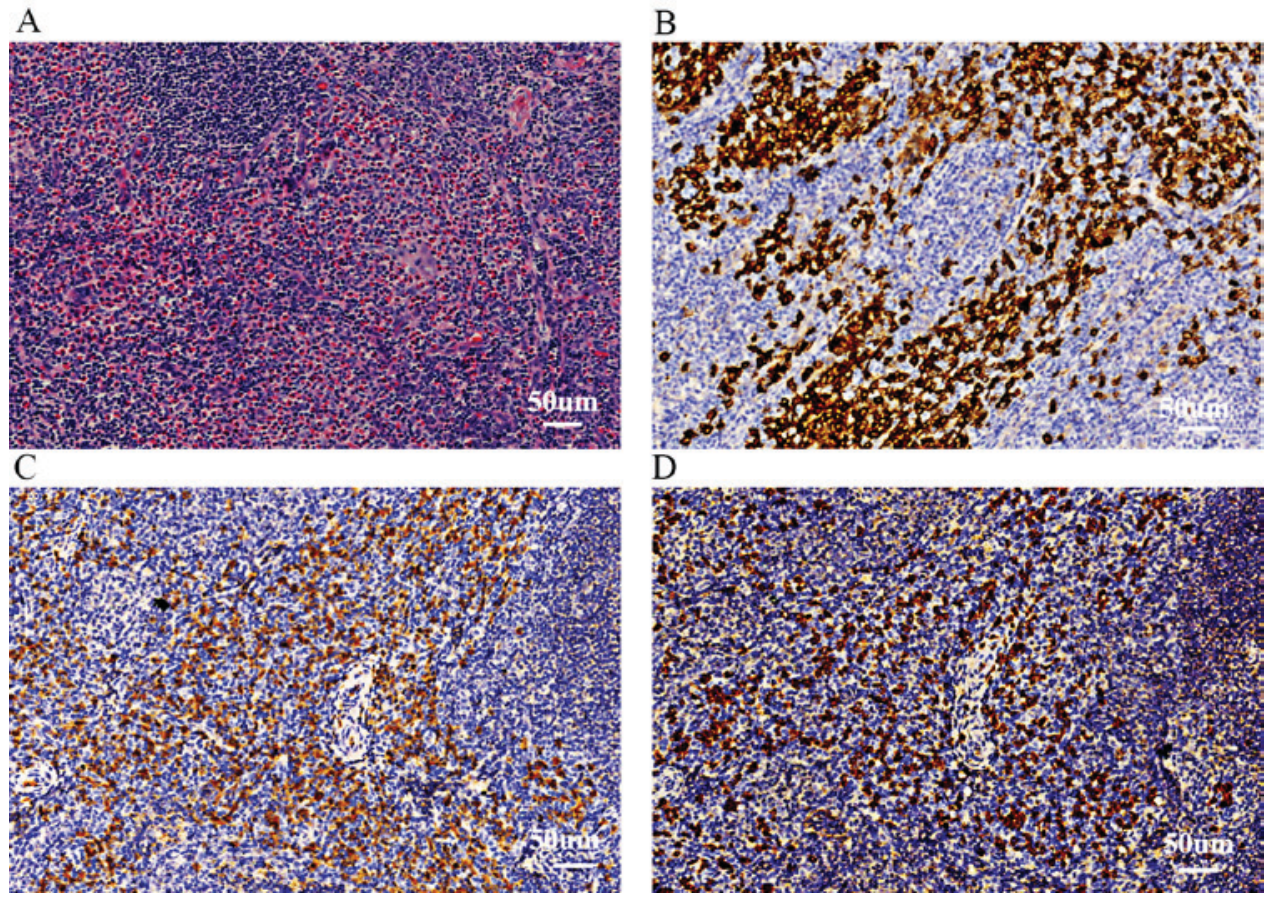

Figure 1. Cervical lymph node cell infiltration. (A) Eosinophil infiltration (>80\% of infiltrating cells; hematoxylin and eosin staining; magnification, $\mathrm{x} 100)$ and (B) CD138+ plasma cell infiltration ( $<20 \%$ of infiltrating cells; CD138 staining; magnification, $x 100)$ in the tissue. (C) IgG+ and (D) IgG4+ cell infiltration in the tissue (IgG4/IgG=50\%; IgG and IgG4 stained respectively; magnification, $\mathrm{x} 100$ ). IgG, immunoglobulin G.

Systems Inc., Tucson, AZ, USA). The following antibodies were used in this analysis: CD2 (cat. no. UMAB6; 1:100), CD3 (cat. no. SP(F); 1:100), CD5 (cat. no. UMAB9; 1:100), CD20 (cat. no. L26; 1:200), CD79a (cat. no. SP18; 1:200), CD138 (cat. no. EP201; 1:300), IgG (cat. no. RA; 1:3,000), IgG4 (cat. no. RA; 1:3,000), Ki-67 (cat. no. UMAB107; 1:100). All antibodies were purchased from Dako; Agilent Technologies, Inc. (Santa Clara, CA, USA). Expression intensity was determined with a scoring system based on the immunoreactive score (IRS) system proposed by Kay et al (15) using 5 random fields of view (magnification, $\mathrm{x} 200$ ). The point system was based on staining strength and was as follows: i) 0 points for no staining; ii) 1 point for a light yellow stain; iii) 2 points for medium yellow or brown appearance without background staining or a deep brown stain with light brown background and iv) 3 points for a deep brown appearance without background staining. The percentage of positive cells was then calculated using 5 random fields of view with a light microscope (magnification, x40) and points were allocated based on their values: i) 0 points for $0 \%$ positive cells; ii) 1 point for $0-25 \%$ positive cells; iii) 2 points for $25-50 \%$ positive cells; iv) 3 points for $50-75 \%$ positive cells; and v) 4 points for $>75 \%$ positive cells. The points allocated from staining strength and the percentage of positive cells were added together. Final scores of $0,1-3,4-5$ and 6-7 were deemed negative (-), weak $(+)$, focal $(++)$ and strong $(+++)$, respectively. Thus, the results of immunohistochemistry were as follows: CD2 focal $(++)$; CD3 focal (++); CD5 focal (++); CD20 focal (++); CD79 $\alpha$ focal $(++)$; S100 focal (++); CD1 $\alpha$ focal (++); CD68 focal (++); CD13 weak (+); CD34 (-); myeloperoxidase weak (+); CD138 focal (++); IgG focal (++); IgG4 focal (++); IgG4/IgG=50\% (Fig. $1 \mathrm{C}$ and D).

Peripheral blood flow cytometric analysis was then performed. All analyses were performed according to standard techniques using a FACS CantoTM II (BD Biosciences, Franklin
Lakes, NJ, USA). The panel of fluorochrome conjugated monoclonal antibodies presented in Table I (mAbs; dilution: 1:2) were utilized to diagnose and classify each cell group, including lymphocytes. A total of $100 \mu 1$ peripheral blood was obtained from the patient. The sample was stained with 1 test $\mathrm{mAb}$ for each marker ( $20 \mu \mathrm{l}$ mAbs conjugated to FITC/PE; $5 \mu \mathrm{l}$, all other $\mathrm{mAbs}$ ) and then incubated for $20 \mathrm{~min}$ at room temperature in dark. A total of $1 \mathrm{ml}$ of 1xBD FACS Lysing solution (cat. no. 349202; BD Biosciences) was added and cell suspensions were washed once with PBS. Cells were vortexed at a speed of $850 \mathrm{x}$ g for $5 \mathrm{~min}$ at $37^{\circ} \mathrm{C}$. Cells were then washed once with PBS and pellets were resuspended in $300 \mu \mathrm{l}$ PBS. A total of $500 \mu 1$ 1X Permabilizing Solution 2 (cat. no. GAS002S100; Invitrogen; Thermo fisher Scientific, Inc.) were added to the cell pellet for the staining of intracellular antibodies and then incubated for $10 \mathrm{~min}$ at room temperature in the dark. Following incubation, cells were centrifuged at a speed of $850 \mathrm{x}$ g for $5 \mathrm{~min}$ at $37^{\circ} \mathrm{C}$. MPO and cCD79a were subsequently added to the cell pellet and incubated for $20 \mathrm{~min}$ at room temperature in the dark. Samples were then analyzed using a flow cytometer (FACS CantoTM II; BD Biosciences) with Cell Quest soft (BD Biosciences; version 5.1) software. The results confirmed that the rate of EOS was increased (48.9\%; normal range, 0.4-8.0\%).

An analysis of the patient's genes was then conducted. For all genes analyzed. RNA was extracted from patient heparinized blood using an OMEGA Blood RNA Maxi kit (Omega Bio-Tek, Inc., Norcross, GA, USA). cDNA was constructed via reverse transcription using random ligomer Primers (6 mer; Takara Biotechnology Co., Ltd., Dalian, China) and cDNA synthesis was performed using a PrimeScript ${ }^{\mathrm{TM}}$ RT reagent kit (Takara Biotechnology Co., Ltd.) following the manufacturer's protocol. Quantitative-polymerase chain reaction (qPCR) was then performed using a $20 \mu \mathrm{l}$ system, containing $16 \mu \mathrm{l}$ 
Table I. Monoclonal antibodies utilized for the identification of each cell group.

\begin{tabular}{|c|c|c|c|}
\hline Cell & Panel & Conjugate & $\begin{array}{c}\text { Catalogue } \\
\text { number }\end{array}$ \\
\hline \multirow[t]{22}{*}{ Lymphocytes } & HLA-DR & APC-CY7 & 335796 \\
\hline & CD2 & FITC & 347593 \\
\hline & CD3 & $\mathrm{PE}$ & 347347 \\
\hline & CD4 & PE-CY7 & 348789 \\
\hline & CD5 & APC & 340583 \\
\hline & CD7 & $\mathrm{PE}$ & 340581 \\
\hline & CD8 & APC-CY7 & 348793 \\
\hline & CD10 & PE-CY7 & 341092 \\
\hline & CD11b & APC & 301310 \\
\hline & CD16 & APC-CY7 & 302018 \\
\hline & CD19 & APC & 652804 \\
\hline & $\mathrm{CD} 20$ & APC-CY7 & 335829 \\
\hline & CD22 & $\mathrm{PE}$ & 347577 \\
\hline & CD34 & FITC & 348053 \\
\hline & CD38 & PE-CY7 & 303516 \\
\hline & CD56 & PE-CY7 & 335791 \\
\hline & cCD79a & $\mathrm{PE}$ & 340579 \\
\hline & cCD3 & $\mathrm{PE}$ & 347347 \\
\hline & $\mathrm{TdT}$ & FITC & 347194 \\
\hline & sKappa & FITC & 349516 \\
\hline & sLambda & $\mathrm{PE}$ & 349516 \\
\hline & CD45 & Percp & 347464 \\
\hline \multirow[t]{13}{*}{ Monocyte } & HLA-DR & APC-CY7 & 335796 \\
\hline & CD11b & APC & 301310 \\
\hline & CD13 & PE & 347837 \\
\hline & CD14 & APC-CY7 & 333951 \\
\hline & CD15 & FITC & 332778 \\
\hline & CD16 & APC-CY7 & 302018 \\
\hline & CD33 & APC & 340474 \\
\hline & CD34 & FITC & 348053 \\
\hline & CD38 & PE-CY7 & 303516 \\
\hline & CD64 & FITC & 555527 \\
\hline & CD117 & PE & 340529 \\
\hline & MPO & FITC & 340580 \\
\hline & CD45 & Percp & 347464 \\
\hline \multirow[t]{11}{*}{ Granulocyte } & HLA-DR & APC-CY7 & 335796 \\
\hline & CD11b & APC & 301310 \\
\hline & CD13 & PE & 347837 \\
\hline & CD15 & FITC & 332778 \\
\hline & CD16 & APC-CY7 & 302018 \\
\hline & CD33 & APC & 340474 \\
\hline & CD34 & FITC & 348053 \\
\hline & CD38 & PE-CY7 & 303516 \\
\hline & CD64 & FITC & 555527 \\
\hline & CD117 & $\mathrm{PE}$ & 340529 \\
\hline & MPO & FITC & 340580 \\
\hline
\end{tabular}

Table I. Continued.

\begin{tabular}{lccc}
\hline Cell & Panel & Conjugate & $\begin{array}{c}\text { Catalogue } \\
\text { number }\end{array}$ \\
\hline & CD45 & Percp & 347464 \\
\hline $\begin{array}{l}\text { HLA-DR, human } \\
\text { allophycocyanin-cyanine7; CD, cluster of Differentiation; FITC, }\end{array}$ \\
$\begin{array}{l}\text { fluorescein; PE, propidium iodide; TdT, terminal deoxynucleotidyl } \\
\text { transferase; Percp, peridinin-chlorophyll-protein complex; MPO, } \\
\text { myeloperoxidase. }\end{array}$ \\
\hline
\end{tabular}

pre-mixed solution [10 $\mu$ l Promega GoTaq Green Mix (Promega Corporation, Madison, WI, USA) and $6 \mu \mathrm{l}$ double distilled (dd) $\left.\mathrm{H}_{2} \mathrm{O}\right], 2 \mu \mathrm{l}$ of specific primers (all, Invitrogen; Thermo Fisher Scientific, Inc.) and $2 \mu \mathrm{l}$ cDNA, positive control samples, negative control samples or $\mathrm{ddH}_{2} \mathrm{O}$. The primers utilized for each gene and the thermocycling conditions of PCR are presented in Tables II and III respectively. PCR products were separated by electrophoresis using $2 \%$ agarose gel. Products were analyzed using the Bio-Rad ChemiDoc XRS+ Gene Genius Bio-imaging system (Bio-Rad Laboratories, Inc., Hercules, CA, USA). PCR products were subsequently separated by electrophoresis using $2 \%$ agarose gel. Products were analyzed using the Bio-Rad ChemiDoc XRS+ Gene Genius Bio-imaging system (Bio-Rad Laboratories, Inc., Hercules, CA, USA). The appearance of specific amplification strips relevant to each gene indicated a positive result. These were as follows: i) BCR/ABL: b3a2, 360 bp, b2a2 and 285 bp; ii) JAK2-V617F: 203 bp and 364 bp; iii) FIP1L1/PDGFRA: 700 bp; iv) ETV6/PDGFRB: 700 bp.

The results of the gene analysis were negative for janus kinase-V617F, breakpoint cluster region protein/abelson murine leukemia viral oncogene homolog 1 fusion, PDGFRA/retinoblastoma protein and ETV6/PDGFRB.

A two-color fluorescence in situ hybridization (FISH) was then performed for the detection of a CHIC2 deletion, acting as a surrogate marker for the FIP1L1-PDGFRA fusion gene at 4q12. Patient peripheral blood was sampled and 24010 (telomeric of PDGFRA), 3H20 (between FIP1L1 and PDGFRA) and Bacterial artificial chromosome (BAC) clones 120K16 (centromeric of FIP1L1) were used as probes (Abbott, 05N52-020). For PDGFRB and FGFR1, the probe was from Abbott (06N24-010) and CYTOTEST (CT-PACO56-10-GO) respectively. FISH data were collected using an Olympus fluorescence microscope (Provis, Olympus Corporation, Tokyo, Japan) and analyzed using ASI-fishview expo 6.0 analyze system software (Applied Spectral Imaging, Inc., Carlsbad, CA, USA). The results demonstrated that there was a negative expression of PDGFRA/RB- and fibroblast growth factor receptor 1 .

Cytokine measurements were then obtained from the patient. IL-1 $\beta$ (cat. no. KT98060), IL-6 (cat. no. kt34251), IL-8 (cat. no. KT98090), IL-10 (cat no. KT98105), TNF- $\alpha$ (cat. no. KT98069) were measured (all kits were sourced from Bender MedSystems, Burlingame, CA, USA) using a Siemens Immulite ${ }^{\circledR} 1000$ (Siemens Healthineers, Erlangen, Germany). The results identified increased levels of interleukin (IL)-6 (38.3 pg/ml; normal range 0-3.4 pg/ml), tumor necrosis 
Table II. Forward and reverse primers of each gene utilized in PCR.

\begin{tabular}{|c|c|c|}
\hline Gene & First primer & Reverse primer \\
\hline $\mathrm{BCR} / \mathrm{ABL}$ & 5'-TCCGCTGACCATCAATAAGGA-3' & 5'-CACTCAGACCCTGAGGCTCAA-3' \\
\hline JAK2-V617F & 5'-TGCTGAAAGTAGGAGAAAGTGCAT-3' & 5'-TCCTACAGTGTTTTCAGTTTCAA-3' \\
\hline \multicolumn{3}{|c|}{ FIP1L1/PDGFRA } \\
\hline First PCR & FIP1L1-F1, 5'-ACCTGGTGCTGATCTTTCTGAT-3' & $\begin{array}{l}\text { PDGFRA-R1, 5'-TGAGAGCTTGTTTTT } \\
\text { CACTGGA-3' }\end{array}$ \\
\hline Second PCR & FIP1L1-F2, 5'-AAAGAGGATACGAATGGGACTTG-3' & $\begin{array}{l}\text { PDGFRA-R2, 5'-GGGACCGGCTTAAT } \\
\text { CCATAG-3' }\end{array}$ \\
\hline \multicolumn{3}{|c|}{ ETV6/PDGFRB } \\
\hline First PCR & ETV6-3F, 5'-CTGCTGACCAAAGAGGACTT-3' & $\begin{array}{l}\text { PD-C,5'-TGGCTTCTTCTGCCAAA } \\
\text { GCA-3' }\end{array}$ \\
\hline Second PCR & ETV6-J, 5'-TTCACCATTCTTCCACCCTGGA-3' & $\begin{array}{l}\text { PD-J, 5'-GGAGATGATGGTGAGC } \\
\text { ACCA-3' }\end{array}$ \\
\hline
\end{tabular}

Table III. Thermocycling conditions for each gene utilized in PCR.

\begin{tabular}{|c|c|}
\hline Gene & Condition \\
\hline $\mathrm{BCR} / \mathrm{ABL}$ & $\begin{array}{l}10 \mathrm{~min} \text { at } 94^{\circ} \mathrm{C} \text {, followed by } 33 \text { cycles of } 30 \mathrm{sec} \text { at } 94^{\circ} \mathrm{C}, 30 \mathrm{sec} \text { at } 57^{\circ} \mathrm{C}, 45 \mathrm{sec} \text { at } 72^{\circ} \mathrm{C} \text { and } \\
10 \mathrm{~min} \text { at } 72^{\circ} \mathrm{C}\end{array}$ \\
\hline JAK2-V617F & $\begin{array}{l}5 \mathrm{~min} \text { at } 95^{\circ} \mathrm{C} \text { for } 1 \mathrm{cycle} \text {, followed by } 35 \text { cycles of } 30 \mathrm{sec} \text { at } 95^{\circ} \mathrm{C}, 30 \mathrm{sec} \text { at } 57^{\circ} \mathrm{C}, 1 \mathrm{~min} \text { at } \\
72^{\circ} \mathrm{C} \text { and } 7 \mathrm{~min} \text { at } 72^{\circ} \mathrm{C} \text { for } 1 \text { cycle }\end{array}$ \\
\hline \multicolumn{2}{|c|}{ FIP1L1/PDGFRA } \\
\hline First PCR & $\begin{array}{l}10 \mathrm{~min} \text { at } 95^{\circ} \mathrm{C} \text {, followed by } 33 \text { cycles of } 45 \mathrm{sec} \text { at } 95^{\circ} \mathrm{C}, 45 \mathrm{sec} \text { at } 57^{\circ} \mathrm{C}, 75 \mathrm{sec} \text { at } 72^{\circ} \mathrm{C} \text { and } \\
5 \mathrm{~min} \text { at } 72^{\circ} \mathrm{C}\end{array}$ \\
\hline Second PCR & $\begin{array}{l}10 \mathrm{~min} \text { at } 95^{\circ} \mathrm{C} \text {, followed by } 25 \text { cycles of } 30 \mathrm{sec} \text { at } 94^{\circ} \mathrm{C}, 30 \mathrm{sec} \text { at } 60^{\circ} \mathrm{C}, 60 \mathrm{sec} \text { at } 72^{\circ} \mathrm{C} \text { and } \\
5 \mathrm{~min} \text { at } 72^{\circ} \mathrm{C}\end{array}$ \\
\hline \multicolumn{2}{|c|}{ ETV6/PDGFRB } \\
\hline First PCR & $\begin{array}{l}10 \mathrm{~min} \text { at } 95^{\circ} \mathrm{C} \text {, followed by } 28 \text { cycles of } 30 \mathrm{sec} \text { at } 94^{\circ} \mathrm{C}, 45 \mathrm{sec} \text { at } 60^{\circ} \mathrm{C}, 75 \mathrm{sec} \text { at } 72^{\circ} \mathrm{C} \text { and } \\
5 \mathrm{~min} \text { at } 72^{\circ} \mathrm{C}\end{array}$ \\
\hline Second PCR & $\begin{array}{l}10 \mathrm{~min} \text { at } 95^{\circ} \mathrm{C} \text {, followed by } 25 \text { cycles of } 30 \mathrm{sec} \text { at } 94^{\circ} \mathrm{C}, 45 \mathrm{sec} \text { at } 64^{\circ} \mathrm{C}, 60 \mathrm{sec} \text { at } 72^{\circ} \mathrm{C} \text { and } \\
5 \mathrm{~min} \text { at } 72^{\circ} \mathrm{C} \text {. }\end{array}$ \\
\hline
\end{tabular}

PCR, polymerase chain reaction; BCR/ABL, breakpoint cluster region/Abelson murine leukemia viral oncogene homolog 1; JAK2-V617F, janus kinase 2-V617F; FIP1L1/PDGFRA, factor interacting with PAPOLA and CPSF1/platelet-derived growth factor receptor alpha gene; ETV6/PDGFRB, ets variant gene 6/platelet-derived growth factor receptor beta gene.

factor- $\alpha$ (TNF- $\alpha$; $26.3 \mathrm{pg} / \mathrm{ml}$; normal range 0-8.1 pg/ml), IL-1 $\beta$ (27.7 pg/ml; normal range $0-5 \mathrm{pg} / \mathrm{ml})$ and IL-8 $(620 \mathrm{pg} / \mathrm{ml}$; normal range $0-62 \mathrm{pg} / \mathrm{ml}$ ). IL-10 levels were $<5 \mathrm{pg} / \mathrm{dl}$ (normal range $0-9.1 \mathrm{pg} / \mathrm{dl}$ ). The peripheral blood flow cytometric analysis also detected CD19 low CD38+CD20-CD27+ plasmablasts at $4,110 / \mathrm{ml}$ (positive predictive value, $>2,000 / \mathrm{ml}$ ). Following therapy with $20 \mathrm{mg}$ prednisone per day for one week, blood tests were performed twice a week at the hospital until the patient's EOS count was reduced to $5.3 \times 10^{9} / 1$. Following this, the patient was discharged. There after, prednisone treatment was gradually decreased and stopped after 6 months. This consisted of $20 \mathrm{mg}$ for first 2 weeks, $15 \mathrm{mg}$ for the following month, $10 \mathrm{mg}$ for the months after that and $2.5 \mathrm{mg}$ per month for the remainder of the treatment period. The clinical course and concomitant EOS count, IgG4 levels and response to prednisone therapy are demonstrated in Fig. 2. Additionally, a comparison of abdominal CT scans obtained pre- and post-treatment is depicted in Fig. 3. A clinical follow-up was conducted every week during the first 2 months, which included routine blood analysis, routine blood biochemical tests, IgG and IgG4 tests 


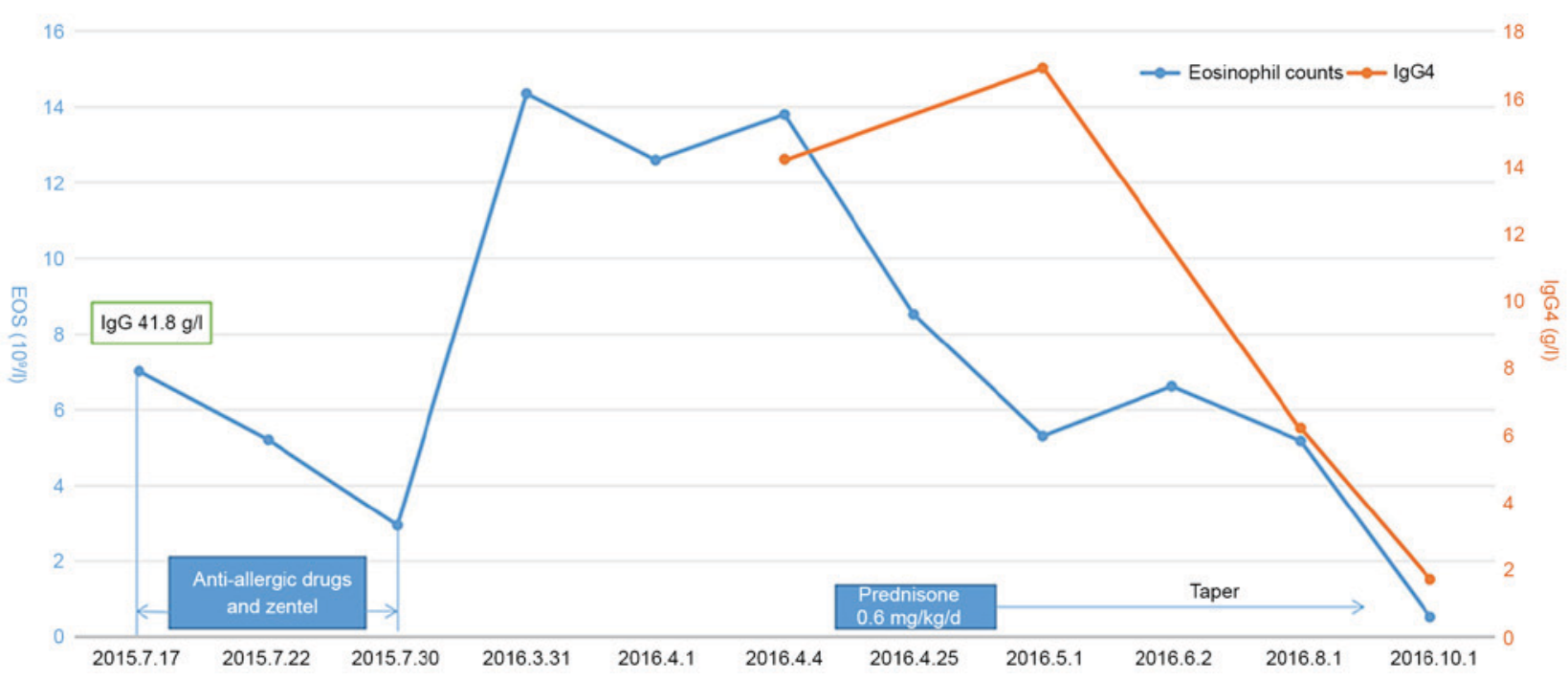

Figure 2. Clinical course and concomitant EOS count, IgG4 levels and response to prednisone therapy. EOS count varied alongside IgG4 levels and both decreased following prednisone therapy. EOS, eosinophils; IgG, immuglobulin G.
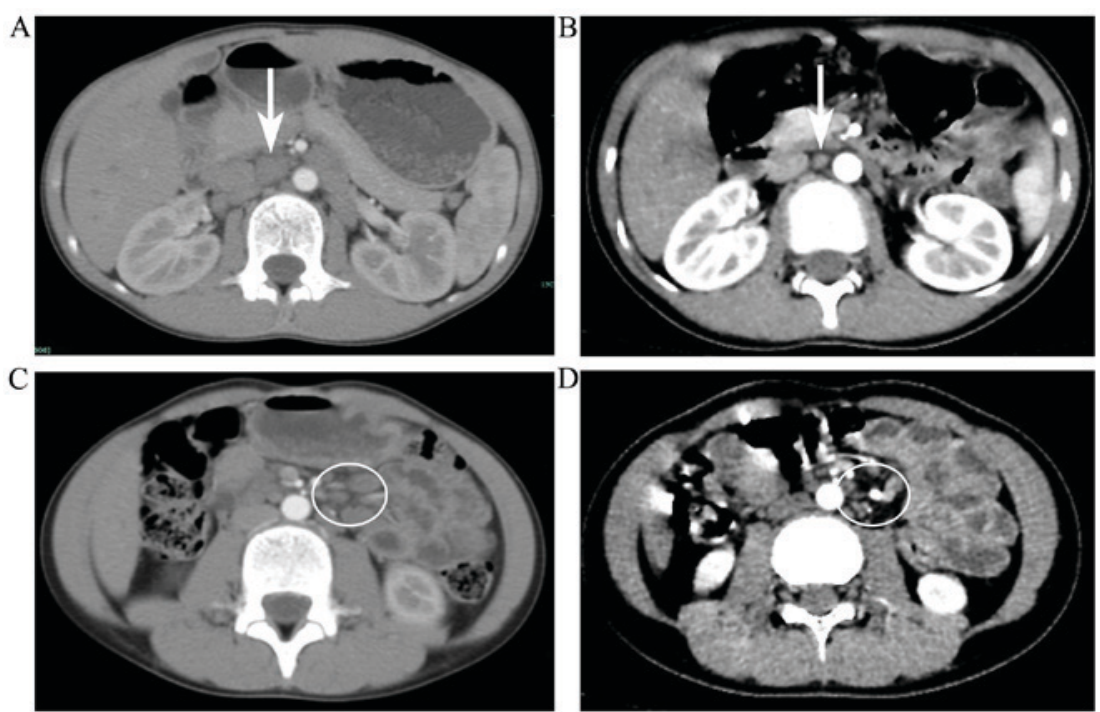

Figure 3. (A-D) Comparison of abdominal CT scans pre- and post-treatment. (A and C) Abdominal CT scans prior to prednisone treatment. (B and D) Abdominal CT scans following prednisone treatment. The abdominal lymphoma nodes in B and D were evidently diminished compared with those in $\mathrm{A}$ and $\mathrm{C}$ (white arrows and circles). CT, computed tomography.

and an abdominal and superficial lymph node ultrasound. An additional follow-up was conducted twice a month during the period of prednisone treatment, which consisted of the same tests conducted in the first 2 months, with the addition of an abdominal CT scan. The patient then received a follow-up every 3 months, which included a systemic examination, blood tests and imageological examination if necessary. The last follow-up was conducted in July 2017 and the boy remains asymptomatic.

\section{Discussion}

The patient initially visited Hangzhou First People's Hospital due to increased levels of EOS and leukocytosis. An allergen test identified an allergy to dust mites. Despite the decrease in EOS count following desensitization therapy, it is unlikely that the patient's condition was solely due to a dust mite allergy that lacked systemic symptoms such as a cough, skin rash or other related reactions. Recurrence of increased EOS count was observed, along with multiple organ infiltration of EOS', which could not be explained by an allergic reaction. The possible diagnoses of clonal eosinophilia and lymphatic variation eosinophilia were excluded according to the results of peripheral blood flow cytometry, gene analysis and FISH. The patient was also treated with antiparasitics but treatment was not effective. Thus, secondary eosinophilia caused by parasites or drugs was excluded. A lymph node biopsy identified infiltration of EOS, which indicated a diagnosis of HES. However, the patient exhibited high levels of IgG4 and imaging examinations, including those of the retroperitoneal and whole body lymph nodes and thalamic region, indicated a diagnosis of IgG4-RD, which required further differentiation from HES secondary to IgG4-RD. 


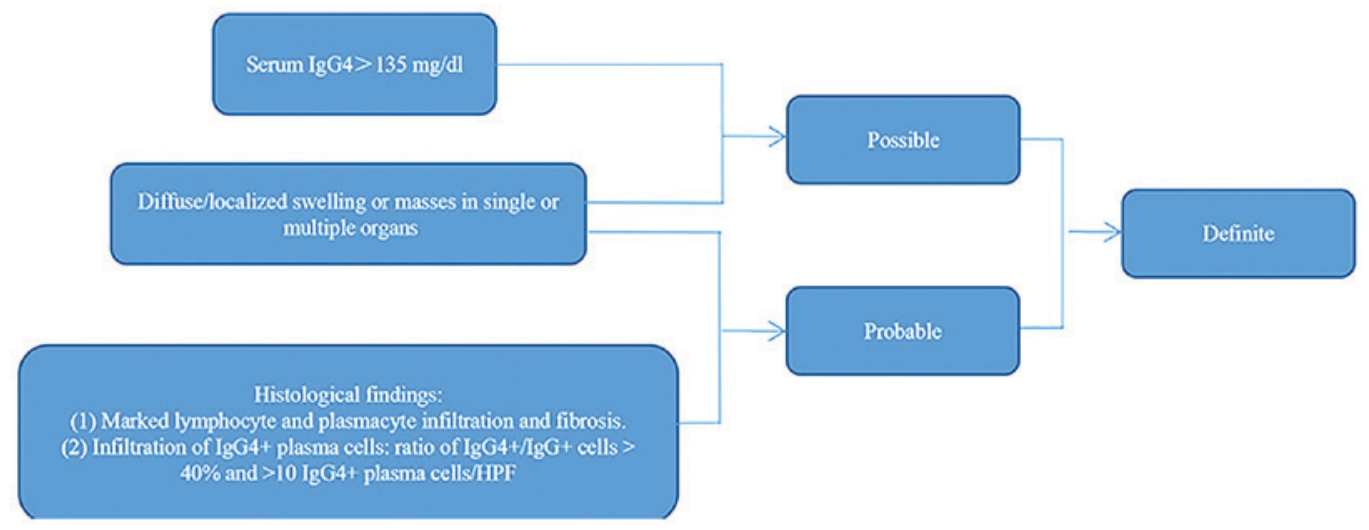

Figure 4. Diagnostic criteria for IgG4-related disease proposed by Umehara et al (16) in 2012. IgG, immunoglobulin G; HPF, high-powered field.

According to the diagnostic criteria for IgG4-RD proposed by the Japanese G4 team in 2012 (16) (Fig. 4), a consensus has been reached on two essential diagnostic criteria: i) serum IgG4 concentration $>135 \mathrm{mg} / \mathrm{dl}$ and ii) $\mathrm{IgG} 4+/ \mathrm{IgG}+$ plasma cells $>40 \%$ and $>10$ IgG4+ cells per high-power field of biopsy samples. Storiform fibrosis and obliterative phlebitis may be clearly identified in pancreatic, biliary tract and retroperitoneal lesions, but are rarely observed in the salivary glands or lymph nodes. The patient was highly suspected to have IgG4-related lymphadenopathy, due to the presence of enlarged lymph nodes and results of biopsy.

IgG4-related lymphadenopathy is characterized by diffuse lymphoplasmacytic infiltration, an increased percentage of IgG4 (+) plasma cells and fibrosis and should be tested for reactive lymphoid hyperplasia, Castleman's disease, inflammatory pseudotumor and angioimmunoblastic $\mathrm{T}$ cell lymphoma (17). Furthermore, IgG4-related lymphadenopathy may be characterized into five histological subtypes: Multicentric Castleman's disease-like, reactive follicular hyperplasia-like, reactive follicular hyperplasia, progressively transformed germinal center-type and inflammatory pseudotumor-like IgG4-related lymphadenopathy (18). The first two subtypes are characterized by systemic lymphadenopathy, while the last three subtypes primarily involve local lymph nodes (19). Based on the infiltrative patterns of IgG4-positive cells, IgG4-related lymphadenopathy can also be divided into interfollicular plasmacytosis and germinal center types (20). Additionally, the diagnosis of IgG4-related lymphadenopathy requires awareness and a high index of suspicion regarding unexplained lymphadenopathy with scattered EOSs and numerous plasma cells (20). In the present case, histological results were not specific to IgG4-related lymphadenopathy due to a lack of fibrosis. However, the abundant infiltration of plasma cells and EOS prompted a careful diagnosis. Immunohistochemical studies are also important in the pathological diagnosis of IgG4-RD (21). In the present case, the ratio of $\operatorname{IgG} 4 / \operatorname{IgG}$ was increased to $50 \%$, which supports the diagnosis of IgG4-RD. Blood plasmablast concentrations may be more meaningful than serum IgG4 levels for the diagnosis of IgG4-RD (14). Additionally, a study by Wallace et al (22) observed that patients with IgG4-RD exhibited markedly increased total plasmablast counts (median: 4,698/ml; range: $610-79,524 / \mathrm{ml}$ ), which was also evaluated in the current patient $(4,110 / \mathrm{ml}$, positive predictive value: $>2,000 / \mathrm{ml})$, thus verifying that plasmablast counts are a potentially useful biomarker for the diagnosis of IgG4-RD. Considering these previous findings and the present clinical data, it is probable that the patient of the present study had IgG4-RD.

The high level of IL-6 also caused difficulty in the diagnosis of the patient, as this is an indicator of Castleman's disease. However, he did not present other associated symptoms, including hypoproteinemia, hypocholesterolemia, anemia and increased C-reactive protein (CRP) levels (23), which did not support the diagnosis of Castleman's disease. IL-6 is a type of a multifunctional cytokine that may regulate the immune and stress responses, haematopoietic function and bone metabolism (23). Masaki et al (24) reported that serum IL-6 was an important tool for differential diagnosis between Castleman's disease and IgG4-RD. However, in a study by Sato et al (25) of 9 patients with IgG4-RD, two patients exhibited slightly increased levels IL-6; however lacked increased CRP levels and were responsive to hormone therapy. Another study by Yokoyama (26) documented that increased IL-6 levels $(>25 \mathrm{pg} / \mathrm{ml})$ were present in $7 \%$ of healthy subjects, which indicated that levels of IL-6 may vary among individuals (25). Furthermore, it is difficult to identify IgG4-RD and Castleman's disease when the IL-6 titer may undergo random fluctuations (27).

Nakamura et al (27) reported a patient with increased IL-6 levels of up to $83.5 \mathrm{pg} / \mathrm{ml}$ and complications of IgG4-RD. They also proposed an improved diagnostic criteria for IgG4-RD (Fig. 5), which was based on a study performed by Umehara et al (16). The present case was highly suspected to be IgG4-RD according to the modified criteria.

IgG4-RD is typically observed in older patients, with a median age of onset of 50 years old (28), though a number of studies have reported cases in children (29-51). While no retrospective study has been reported to date, Karim et al (52) recently reviewed published data and performed a systematic literature search of IgG4-RD in pediatrics. The median age of onset was 13 years (3 to 17 years old) and 64\% of patients were girls. IgG4-RD in children is potentially the same as in adults, primarily affecting the orbit, lymph nodes, salivary tract and pancreas $(52,53)$. The percentage of pediatric patients with elevated serum IgG4 levels was $70 \%$, which is similar to that in adult patients (30-50\%) (54). However, the positive predictive value of serum IgG4 is limited. The present diagnosis also required histological observations, assessment of clinical 


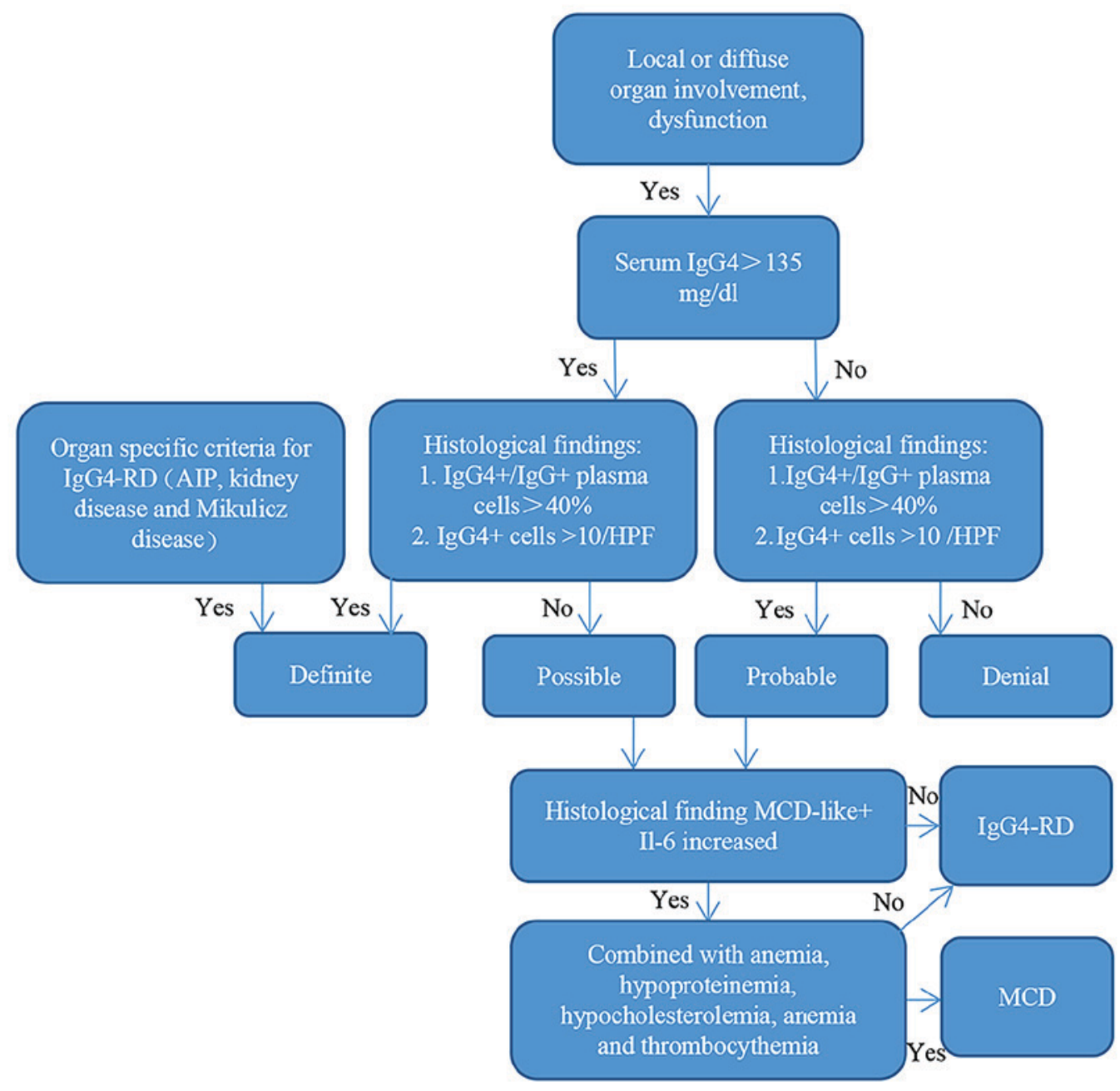

Figure 5. Improved diagnostic criteria for IgG4-RD proposed by Nakamura et al (27). IgG4-RD, immunoglobulin G4-related disease; AIP, autoimmune pancreatitis; MCD, multiple Castleman's disease; IL, interleukin; HPF, high-powered field.

symptoms and serological and radiological observations. The first choice therapy for pediatric IgG4-RD is prednisone, however, no consensus on the dosage has been reached. For cases not responding to prednisone, disease-modifying antirheumatic drugs, including mycophenolate mofetil, azathioprine and methotrexate have demonstrated efficacy in some patients $(38,45,47)$.

Idiopathic HES is rare in children and a limited number of cases have been reported (55-57). The true incidence is unknown and data on the efficacy of treatment regarding the response and survival of patients is also insufficient (55). Pediatric HES has been reported to have a slight male prevalence (56), though a recent study by Williams et al (57) observed that the female/male occurrence ratio was increased to $23 / 9$ (57). Additionally, they documented that children with HES typically exhibit higher peak EOS counts than adults. Presentation of HES is variable, though fever, arthralgias and rash were common presentation symptoms (57). In pediatric idiopathic HES, pulmonary and cardiac involvement may be the most common clinical manifestations (55). However, in the current patient, there was no specific clinical presentation except painless and enlarged lymphoma.

Treatment strategies are based on the disease severity. Prevention of organ dysfunction and reductions in EOS count are priority and corticosteroids are recommended as the first-line therapy for HES (5). To the best of our knowledge, no published data has demonstrated a relationship between HES and IgG4-RD in children, whereas several studies (58-61) have described a potential correlation between these two illnesses in adults.

Previous studies have reported that an immune reaction mediated by $\mathrm{T}$ helper ( $\mathrm{Th}$ ) 2 cells is predominant in IgG4-RD (62), which may contribute to disease pathogenesis $(63,64)$. However, Th2 memory cells have not been detected in a large number of individuals with severe IgG4-RD, despite the patients didn't having undergone immunosuppressive therapy (62). Therefore, a Th2 immune response in IgG4-RD may not represent a fundamental feature of IgG4-RD but rather a potential phenomenon or process (62). Additionally, cytokines IL-4, IL-5 and IL-13 that are secreted by Th2 cells may induce the transition between $\operatorname{IgG}$ and $\operatorname{IgE}$ and promote the release of PBEs (65). A recent study evaluated a large cohort of IgG4-RD patients exhibiting multiple organ involvement and indicated that processes inherent to IgG4-RD itself rather than atopy may contribute to eosinophilia and IgE elevation (66). The median count of EOS in IgG4-RD was 641 cells/ $\mu$ l (ranging between 40 to 1,500 cells/ $\mu$ l) (66), which differs to that of the current patient (2,940-12,600 cells/ $\mu \mathrm{l})$. Thus, combined with the pathological observations and clinical features, a diagnosis of IHES was more probable. 
Hypereosinophilia and high levels of IgE may cause T-reg cells to secrete IL-10 and tumor growth factor $\beta$ and increase the serum titer of IgG4 (67). IL-10 is often overexpressed in IgG4-RD (68). Furthermore, hypereosinophilia and IgG4-RD can occur at the same time (58). In the current patient, increased levels of EOS and serum IgG4 were concurrent with a low titer of IL-10, which indicated that elevated IgG4 was not simply due to HES. To date, the correlation between HES and IgG4-RD remains unclear (14). A study by Tabata et al (69) reviewed 554 IgG4-RD patients who had their IgG4 levels measured and $2 / 16$ patients with HES exhibited an increased serum titer of IgG4. Although the author did not confirm the diagnosis of IgG4-RD in the two patients, one of them was sensitive to hormone therapy.

Existing data on the concurrence of HES with IgG4-RD is rare. Nagao et al (59) reported a patient with lymphoproliferative variant HES who was highly suspected to have IgG4-RD, which was combined with an increased titer of TNF- $\alpha$ and IL-10. Aoyama et al (60) also reported a case of HES-related acute hepatitis caused by HES and associated with elevated serum IgG4 levels, which is similar to the results reported by Nagamura et al (58). They concluded that HES associated with an elevated concentration of serum IgG4 is difficult to differentiate from IgG4-RD and a careful diagnosis based on clinical symptoms and pathological observations is required which is also agreed by Aoyama et al (60). Clayton et al (61) hypothesized that in adults, eosinophilic esophagitis may be mediated by IgG4 and not an IgE-induced allergy. Existing data on concurrent HES and IgG4-RD lacks full support of the pathology. These data indicate that the association between HES and IgG4-RD remains unclear and further studies are required to focus on the mechanism between these two illnesses.

In conclusion, the present study described a case of HES with highly suspected IgG4-RD. However, due to insufficient pathological observations, a definitive pathological diagnosis of IgG4-RD could not be made. Nevertheless, the clinical presentation, immunohistochemical observations, abundant peripheral blood plasmablast and response to prednisone therapy confirmed the diagnosis. As IgG4-RD typically affects middle-aged and elderly males, published cases of IgG4-RD in children are extremely rare. Therefore, the present case serves as a reminder that IgG4-RD may occur in children and clinical doctors should not neglect the possibility of IgG4-RD in children.

\section{References}

1. Tefferi A, Gotlib J and Pardanani A: Hypereosinophilic syndrome and clonal eosinophilia: Point-of-care diagnostic algorithm and treatment update. Mayo Clinic Proc 85: 158-164, 2010.

2. Crane MM, Chang CM, Kobayashi MG and Weller PF: Incidence of myeloproliferative hypereosinophilic syndrome in the United States and an estimate of all hypereosinophilic syndrome incidence. J Allergy Clin Immunol 126: 179-181, 2010.

3. Tefferi A, Patnaik MM and Pardanani A: Eosinophilia: Secondary, clonal and idiopathic. Br J Haematol 133: 468-492, 2006.

4. Ganeva M, Gancheva T, Lazarova R, Troeva J, Baldaranov I, Vassilev I, Hristakieva E and Tzaneva V: Carbamazepine-induced drug reaction with eosinophilia and systemic symptoms (DRESS) syndrome: Report of four cases and brief review. Int J Dermatol 47: 853-860, 2008.

5. Gotlib J: World Health Organization-defined eosinophilic disorders: 2014 update on diagnosis, risk stratification, and management. Am J Hematol 89: 325-337, 2014.
6. Vardiman JW: The World Health Organization (WHO) classification of tumors of the hematopoietic and lymphoid tissues: An overview with emphasis on the myeloid neoplasms. Chem Biol Interact 184: 16-20, 2010.

7. Schaller JL and Burkland GA: Case report: Rapid and complete control of idiopathic hypereosinophilia with imatinib mesylate. MedGenMed 3: 9, 2001.

8. Cheah CY, Burbury K, Apperley JF, Huguet F, Pitini V, Gardembas M, Ross DM, Forrest D, Genet P, Rousselot P, et al: Patients with myeloid malignancies bearing PDGFRB fusion genes achieve durable long-term remissions with imatinib. Blood 123: 3574-3577, 2014.

9. Ogbogu PU, Bochner BS, Butterfield JH, Gleich GJ, Huss-Marp J, Kahn JE, Leiferman KM, Nutman TB, Pfab F, Ring J, et al: Hypereosinophilic syndromes: A multicenter, retrospective analysis of clinical characteristics and response to therapy. J Allergy Clin Immunol 124: 1319-1325.e3, 2009.

10. Fauci AS, Harley JB, Roberts WC, Ferrans VJ, Gralnick HR and Bjornson BH: NIH conference. The idiopathic hypereosinophilic syndrome. Clinical, pathophysiologic, and therapeutic considerations. Ann Intern Med 97: 78-92, 1982.

11. Quiquandon I, Claisse JF, Capiod JC, Delobel J and Prin L: alpha-Interferon and hypereosinophilic syndrome with trisomy 8 : Karyotypic remission. Blood 85: 2284-2285, 1995.

12. Cofrancesco E, Cortellaro M, Pogliani E, Boschetti C, Salvatore M and Polli EE: Response to vincristine treatment in a case of idiopathic hypereosinophilic syndrome with multiple clinical manifestations. Acta Haematol 72: 21-25, 1984.

13. Umehara H, Okazaki K, Masaki Y, Kawano M, Yamamoto M, Saeki T, Matsui S, Sumida T, Mimori T, Tanaka Y, et al: A novel clinical entity, IgG4-related disease (IgG4RD): General concept and details. Mod Rheumatol 22: 1-14, 2012.

14. Stone JH, Brito-Zerón P, Bosch X and Ramos-Casals M: Diagnostic approach to the complexity of IgG4-related disease. Mayo Clin Proc 90: 927-939, 2015.

15. Friedrichs K, Gluba S, Eidtmann H and Jonat W: Overexpression of p53 and prognosis in breast cancer. Cancer 72: 3641-3647, 1993.

16. Umehara H, Okazaki K, Masaki Y, Kawano M, Yamamoto M, Saeki T, Matsui S, Yoshino T, Nakamura S, Kawa S, et al: Comprehensive diagnostic criteria for IgG4-related disease (IgG4-RD), 2011. Mod Rheumatol 22: 21-30, 2012.

17. Jingzhi S, Lifang Z and Meiyun F: IgG4-related lymphadenopathy: A case report. Zhong hua shi yong nei ke za zhi 08: 721-723, 2015.

18. Sato Y and Yoshino T: IgG4-related lymphadenopathy. Int J Rheumatol 2012: 572539, 2012.

19. Sato Y, Kojima M, Takata K, Morito T, Mizobuchi K, Tanaka T, Inoue D, Shiomi H, Iwao H and Yoshino T: Multicentric Castleman's disease with abundant IgG4-positive cells: A clinical and pathological analysis of six cases. J Clin Pathol 63: 1084-1089, 2010.

20. Sato Y, Notohara K, Kojima M, Takata K, Masaki Y and Yoshino T: IgG4-related disease: Historical overview and pathology of hematological disorders. Pathol Int 60: 247-258, 2010.

21. Stone JH, Zen Y and Deshpande V: IgG4-related disease. N Engl J Med 366: 539-551, 2012.

22. Wallace ZS, Mattoo H, Carruthers M, Mahajan VS, Della Torre E, Lee H, Kulikova M, Deshpande V, Pillai S and Stone JH: Plasmablasts as a biomarker for IgG4-related disease, independent of serum IgG4 concentrations. Ann Rheum Dis 74: 190-195, 2014.

23. Frizzera G, Peterson BA, Bayrd ED and Goldman A: A systemic lymphoproliferative disorder with morphologic features of Castleman's disease: Clinical findings and clinicopathologic correlations in 15 patients. J Clin Oncol 3: 1202-1216, 1985.

24. Masaki Y, Dong L, Kurose N, Kitagawa K, Morikawa Y, Yamamoto M, Takahashi H, Shinomura Y, Imai K, Saeki T, et al: Proposal for a new clinical entity, IgG4-positive multiorgan lymphoproliferative syndrome: Analysis of 64 cases of IgG4-related disorders. Ann Rheum Dis 68: 1310-1315, 2009.

25. Sato Y, Kojima MK, Takata K, Morito T, Asaoku H, Takeuchi T, Mizobuchi K, Fujihara M, Kuraoka K, Nakai T, et al: Systemic IgG4-related lymphadenopathy: A clinical and pathologic comparison to multicentric Castleman's disease. Mod Pathol 22: 589-599, 2009.

26. Yokoyama A: Interleukin-6 (IL-6)/soluble IL-6 receptor. Nippon Rinsho Japanese J Clin Med 63 (Suppl 8): S72-S74, 2005.

27. Nakamura M, Iwamoto O, Chino T, Todoroki K and Kusukawa J: Diagnostic dilemma of IgG4-related primary localized cervical lymphadenopathy associated with aberrant IL-6 expression level. Diagn Pathol 11: 43, 2016. 
28. Kamisawa T, Zen Y, Pillai S and Stone JH: IgG4-related disease. Lancet 385: 1460-1471, 2015.

29. Bain BJ, Gilliland DG, Vardiman JW and Horny HP: Chronic eosinophilic leukaemia, not otherwise specified, 2008.

30. Batu ED, Arici ZS, Orhan D, Kiratli Hand Özen S: Immunoglobulin G4-related orbital disease: Report of two pediatric cases. Clin Exp Rheum 33: 409-410, 2015.

31. Caso F, Fiocco U,Costa L, Sfriso P,Punzi L and Doria A: Successful use of rituximab in a young patient with immunoglobulin G4-related disease and refractory scleritis. Joint Bone Spine 81: 190-192, 2013

32. Corujeira S, Ferraz C, Nunes T, Fonseca E and Vaz LG: Severe IgG4-related disease in a young child: A diagnosis challenge. Case Rep Pediatr 2015: 140753, 2015.

33. Gillispie MC, Thomas RD and Hennon TR: Successful treatment of IgG-4 related sclerosing disease with rituximab: A novel case report. Clin Exp Rheumatol 33: 549-550, 2015.

34. Griepentrog GJ, Vickers RW, Karesh JW, Azari AA, Albert DM and Bukat CN: A clinicopathologic case study of two patients with pediatric orbital IgG4-related disease. Orbit 32: 389-391, 2013

35. Hasosah MY, Satti MB, Yousef YA, Alzahrani DM, Almutairi SA Alsahafi AF, Sukkar GA and Alzaben AA: IgG4-related sclerosing mesenteritis in a 7-year-old Saudi girl. Saudi J Gastroenterol 20: 385-388, 2014

36. Jariwala MP, Agarwal M, Mulay K and Sawhney S: IgG4-related orbital inflammation presenting as unilateral pseudotumor. Indian J Pediatr 81: 1108-1110, 2014.

37. Kalapesi FB, Garrott HM, Moldovan C, Williams M, Ramanan A and Herbert HM: IgG4 orbital inflammation in a 5-year-old child presenting as an orbital mass. Orbit 32: 137-140, 2013.

38. Mannion M and Cron RQ: Successful treatment of pediatric IgG4 related systemic disease with mycophenolate mofetil: Case report and a review of the pediatric autoimmune pancreatitis literature. Pediatr Rheum Online J 9: 1, 2011

39. Miglani RK, Murthy D, Bhat R and Kumar AK: Immunoglobulin G4-associated cholangitis mimicking cholangiocarcinoma in a young boy. J Postgrad Med 56: 140-142, 2010.

40. Mittal R, Ganguly A, Rath S, Das B and Mishra A: IgG4-related orbital inflammation presenting as bilateral proptosis in a child Eye (Lond) 28: 1264-1266, 2014

41. Nada R, Gupta A, Kang M, Rawat A, Sood A, Ahluwalia J and Singh S: Hepatic mass and coagulopathy in a ten-year-old boy with fever. Arthritis Rheumatol 67: 1977, 2015.

42. Naghibi M, Ahmed A, al Badri AM, Bateman AC, Shepherd HA and Gordon JN: The successful treatment of IgG4-positive colitis with adalimumab in a patient with IgG4-related sclerosing disease-a new subtype of aggressive colitis? J Crohns Colitis 7: e81-e84, 2013.

43. Pasic S, Ristic G and Djuricic S: PReS-FINAL-2276: IgG4 related disease in a 10-year-old girl. Pediatr Rheumatol Online J 11 (Suppl 2): P266, 2013.

44. Prabhu SM, Yadav V, Irodi A, Mani S and Varghese AM: IgG4-related disease with sinonasal involvement: A case series. Indian J Radiol Imaging 24: 117-120, 2014

45. Sane M, Chelnis J, Kozielski R and Fasiuddin A: Immunoglobulin G4-related sclerosing disease with orbital inflammation in a 12-year-old girl. J AAPOS 17: 548-550, 2013.

46. Zakeri H and Kashi Z: Variable clinical presentations of Riedel's thyroiditis: Report of two cases. Case Rep Med 2011: 709264, 2011

47. Ibrahim SH, Zhang L and Freese DK: A 3-year-old with immunoglobulin G4-associated cholangitis. J Pediatr Gastroenterol Nutr 53: 109-111, 2011.

48. Melo JC, Kitsko D and Reyes-Múgica M: Pediatric chronic sclerosing sialadenitis: Küttner tumor. Pediatr Dev Pathol 15: 165-169, 2012 .

49. Notz G, Intili A and Bilyk JR: IgG4-related dacryoadenitis in a 13-year-old girl. Ophthal Plast Reconstr Surg 30: e161-e163, 2014.

50. Pifferi M, Di Cicco M, Bush A, Caramella D, Chilosi M and Boner AL: Uncommon pulmonary presentation of IgG4-related disease in a 15-year-old boy. Chest 144: 669-671, 2013.

51. Rosen D, Thung S, Sheflin-Findling S, Lai J, Rosen A, Arnon R and Chu J: IgG4-sclerosing cholangitis in a pediatric patient. Semin Liver Dis 35: 89-94, 2015.

52. Karim F, Loeffen J, Bramer W, Westenberg L, Verdijk R, van Hagen M and van Laar J: IgG4-related disease: A systematic review of this unrecognized disease in pediatrics. Pediatr Rheumatol Online J 14: 18, 2016.
53. Islam AD, Selmi C, Datta-Mitra A, Sonu R, Chen M, Gershwin ME and Raychaudhuri SP: The changing faces of IgG4-related disease: Clinical manifestations and pathogenesis. Autoimmun Rev 14: 914-922, 2015.

54. Pieringer H, Parzer I, Wöhrer A, Reis P, Oppl B and Zwerina J: IgG4- related disease: An orphan disease with many faces. Orphanet J Rare Dis 9: 110, 2014.

55. Tavil B, Aytac S, Unal S, Kuskonmaz B, Gumruk F and Cetin M: Hypereosinophilic syndrome: Hacettepe experience. J Pediatr Hematol Oncol 38: 539-543, 2016.

56. Alfaham MA, Ferguson SD, Sihra B, et al: The idiopathic hypereosinophilic syndrome. Arch Dermatol 132: 583-585, 2001.

57. Williams K. Ware JA, Abiodun A, Holland-Thomas NC, Khoury P and Klion AD: Hypereosinophilia in children and adults: A retrospective comparison. J Allergy Clin Immunol Pract 4: 941-947. e1, 2016.

58. Nagamura N, Ueno S, Fujishiro H and Oonuma H: Hepatitis associated with hypereosinophilia suspected to be caused by HES that also presented with the pathological features of IgG4-related disease. Intern Med 53: 145-149, 2014.

59. Nagao Y, Yamanaka $\mathrm{H}$ and Harada $\mathrm{H}$ : A patient with hypereosinophilic syndrome that manifested with acquired hemophilia and elevated IgG4: A case report. J Med Case Rep 6: 63, 2012.

60. Aoyama T, Matsumoto T, Uchiyama A, Kon K, Yamashina S, Suzuki S, Ikejima K, Yao T, Kuwatsuru R and Watanabe S: Recurrent severe acute hepatitis caused by hypereosinophilic syndrome associated with elevated serum immunoglobulin G4 levels. Clin J Gastroenterol 7: 516-522, 2014.

61. Clayton F, Fang JC, Gleich GJ, Lucendo AJ, Olalla JM, Vinson LA, Lowichik A, Chen X, Emerson L, Cox K, et al: Eosinophilic esophagitis in adults is associated with IgG4 and not mediated by IgE. Gastroenterology 147: 602-609, 2014.

62. Mattoo H, Della-Torre E, Mahajan VS, Stone JH and Pillai S: Circulating Th2 memory cells in IgG4-related disease are restricted to a defined subset of subjects with atopy. Allergy 69: 399-402, 2014.

63. Zen Y, Fujii T, Harada K, Kawano M, Yamada K, Takahira M and Nakanuma Y: Th2 and regulatory immune reactions are increased in immunoglobin G4-related sclerosing pancreatitis and cholangitis. Hepatology 45: 1538-1546, 2007.

64. Tanaka A, Moriyama M, Nakashima H, Miyake K, Hayashida JN, Maehara T, Shinozaki S, Kubo Y and Nakamura S: Th2 and regulatory immune reactions contribute to IgG4 production and the initiation of Mikulicz disease. Arthr Rheum 64: 254-263, 2012.

65. Okazaki K, Uchida K, Ohana M, Nakase H, Uose S, Inai M, Matsushima Y, Katamura K, Ohmori K and Chiba T: Autoimmune-related pancreatitis is associated with autoantibodies and a Th1/Th2-type cellular immune response. Gastroenterology 118: 573-581, 2000.

66. Della Torre E, Mattoo H, Mahajan VS, Carruthers M, Pillai S and Stone JH: Prevalence of atopy, eosinophilia, and IgE elevation in IgG4-related disease. Allergy 69: 269-272, 2014.

67. Tsuboi H, Matsuo N, Iizuka M, Tsuzuki S, Kondo Y, Tanaka A, Moriyama M, Matsumoto I, Nakamura S and Sumida T: Analysis of IgG4 class switch-related molecules in IgG4-related disease. Arthr Res Ther 14: R171, 2012.

68. Nakashima H, Miyake K, Moriyama M, Tanaka A, Watanabe M, Abe Y, Sato H, Nakamura S and Saito T: An amplification of IL-10 and TGF-beta in patients with IgG4-related tubulointerstitial nephritis. Clin Nephrol 73: 385-391, 2010.

69. Tabata T, Kamisawa T, Takuma K, Egawa N, Setoguchi K, Tsuruta K, Obayashi T and Sasaki T: Serial changes of elevated serum IgG4 levels in IgG4-related systemic disease. Intern Med 50: 69-75, 2011

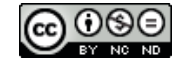

This work is licensed under a Creative Commons Attribution-NonCommercial-NoDerivatives 4.0 International (CC BY-NC-ND 4.0) License. 